\title{
A note on ' $n$-tuplet fixed point theorems for contractive type mappings in partially ordered metric spaces'
}

\author{
Erdal Karapınar ${ }^{1 *}$ and Antonio Roldán²
}

\section{"Correspondence:}

erdalkarapinar@yahoo.com;

ekarapinar@atilim.edu.tr

'Department of Mathematics,

Atilim University, Incek, Ankara 06836, Turkey

Full list of author information is

available at the end of the article

\begin{abstract}
In this note, we show that multidimensional fixed point theorems established in the recent report [M. Ertürk and V. Karakaya, $n$-tuplet fixed point theorems for contractive type mappings in partially ordered metric spaces, Journal of Inequalities and Applications 2013, 2013:196] have gaps. Furthermore, the results of the mentioned paper can be reduced to unidimensional (existing) fixed point theorems.

MSC: $47 \mathrm{H} 10 ; 54 \mathrm{H} 25$
\end{abstract}

Keywords: multidimensional fixed point; partially ordered metric space

\section{Introduction and preliminaries}

Throughout this manuscript, $X$ will be a non-empty set and $\preceq$ will denote a partial order on $X$. Given $n \in \mathbb{N}$ with $n \geq 2$, let us denote by $X^{n}$ the product space $X \times X \times{ }^{(n)} \cdot \cdots \times$ of $n$ identical copies of $X$.

The study of multidimensional fixed point theorems was initiated by Guo and Lakshmikantham in [1] in the coupled case.

Definition 1.1 (Guo and Lakshmikantham [1]) Let $F: X \times X \rightarrow X$ be a given mapping. We say that $(x, y) \in X \times X$ is a coupled fixed point of $F$ if

$$
F(x, y)=x \quad \text { and } \quad F(y, x)=y .
$$

In 2006, Bhaskar and Lakshmikantham [2] proved some coupled fixed point theorems for a mapping $F: X \times X \rightarrow X$ (where $X$ is a partially ordered metric space) by introducing the notion of mixed monotone mapping.

Definition 1.2 (See [2]) Let $(X, \preceq)$ be a partially ordered set. A mapping $F: X \times X \rightarrow X$. $F$ is said to have the mixed monotone property if $F(x, y)$ is monotone nondecreasing in $x$ and is monotone non-increasing in $y$, that is, for any $x, y \in X$,

$$
\begin{array}{lll}
x_{1}, x_{2} \in X, & x_{1} \preceq x_{2} \quad \Rightarrow \quad F\left(x_{1}, y\right) \preceq F\left(x_{2}, y\right) \quad \text { and } \\
y_{1}, y_{2} \in X, & y_{1} \preceq y_{2} \quad \Rightarrow \quad F\left(x, y_{2}\right) \preceq F\left(x, y_{1}\right) .
\end{array}
$$

@2013 Karapınar and Roldán; licensee Springer. This is an Open Access article distributed under the terms of the Creative Commons Attribution License (http://creativecommons.org/licenses/by/2.0), which permits unrestricted use, distribution, and reproduction in any medium, provided the original work is properly cited. 
Following this paper, Lakshmikantham and Ćirić [3] established coupled fixed/coincidence point theorems for mappings $F: X \times X \rightarrow X$ and $g: X \rightarrow X$ by defining the concept of the mixed g-monotone property. Later, Berinde and Borcut studied the tripled case.

Definition 1.3 (Berinde and Borcut [4]) Let $F: X^{3} \rightarrow X$ be a given mapping. We say that $(x, y, x) \in X^{3}$ is a tripled fixed point of $F$ if

$$
F(x, y, z)=x, \quad F(y, x, y)=y \quad \text { and } \quad F(z, x, y)=z .
$$

Definition 1.4 (See [4]) Let $(X, \preceq)$ be a partially ordered set and $F: X^{3} \rightarrow X$. We say that $F$ has the mixed monotone property if $F(x, y, z)$ is monotone non-decreasing in $x$ and $z$, and it is monotone non-increasing in $y$, that is, for any $x, y, z \in X$,

$$
\begin{array}{ll}
x_{1}, x_{2} \in X, \quad x_{1} \preceq x_{2} \quad \Rightarrow \quad F\left(x_{1}, y, z\right) \preceq F\left(x_{2}, y, z\right), \\
y_{1}, y_{2} \in X, \quad y_{1} \preceq y_{2} \quad \Rightarrow \quad F\left(x, y_{1}, z\right) \succeq F\left(x, y_{2}, z\right) \quad \text { and } \\
z_{1}, z_{2} \in X, \quad z_{1} \preceq z_{2} \quad \Rightarrow \quad F\left(x, y, z_{1}\right) \preceq F\left(x, y, z_{2}\right) .
\end{array}
$$

Karapınar and Luong studied the quadruple case.

Definition 1.5 (See [5-7]) An element $(x, y, z, w) \in X^{4}$ is called a quadruple fixed point of $F: X^{4} \rightarrow X$ if

$$
F(x, y, z, w)=x, \quad F(y, z, w, x)=y, \quad F(z, w, x, y)=z \quad \text { and } \quad F(w, x, y, z)=w .
$$

Definition 1.6 (See [5]) Let $(X, \preceq)$ be a partially ordered set and $F: X^{4} \rightarrow X$. We say that $F$ has the mixed monotone property if $F(x, y, z, w)$ is monotone non-decreasing in $x$ and $z$, and it is monotone non-increasing in $y$ and $w$, that is, for any $x, y, z, w \in X$,

$$
\begin{array}{ll}
x_{1}, x_{2} \in X, \quad x_{1} \preceq x_{2} \quad \Rightarrow \quad F\left(x_{1}, y, z, w\right) \preceq F\left(x_{2}, y, z, w\right), \\
y_{1}, y_{2} \in X, \quad y_{1} \preceq y_{2} \quad \Rightarrow \quad F\left(x, y_{1}, z, w\right) \succeq F\left(x, y_{2}, z, w\right), \\
z_{1}, z_{2} \in X, \quad z_{1} \preceq z_{2} \quad \Rightarrow \quad F\left(x, y, z_{1}, w\right) \preceq F\left(x, y, z_{2}, w\right) \quad \text { and } \\
w_{1}, w_{2} \in X, \quad w_{1} \preceq w_{2} \quad \Rightarrow \quad F\left(x, y, z, w_{1}\right) \succeq F\left(x, y, z, w_{2}\right) .
\end{array}
$$

When a mapping $g: X \rightarrow X$ is involved, we have the notion of coincidence point. We will only recall the corresponding definitions in the quadruple case since they are similar in other dimensions.

Definition 1.7 (See [8]) An element $(x, y, z, w) \in X^{4}$ is called a quadrupled coincident point of the mappings $F: X^{4} \rightarrow X$ and $g: X \rightarrow X$ if

$$
g x=F(x, y, z, w), \quad g y=F(y, z, w, x), \quad g z=F(z, w, x, y) \quad \text { and } \quad g w=F(w, x, y, z) .
$$


Definition 1.8 (See [8]) Let $(X, \preceq)$ be a partially ordered set, and let $F: X^{4} \rightarrow X$ and $g$ : $X \rightarrow X$ be two mappings. We say that $F$ has the mixed $g$-monotone property if $F(x, y, z, w)$ is $g$-non-decreasing in $x$ and $z$ and is $g$-non-increasing in $y$ and $w$, that is, for any $x, y, z, w \in X$,

$$
\begin{aligned}
& x_{1}, x_{2} \in X, \quad g x_{1} \preceq g x_{2} \quad \Rightarrow \quad F\left(x_{1}, y, z, w\right) \preceq F\left(x_{2}, y, z, w\right), \\
& y_{1}, y_{2} \in X, \quad g y_{1} \preceq g y_{2} \quad \Rightarrow \quad F\left(x, y_{1}, z, w\right) \succeq F\left(x, y_{2}, z, w\right), \\
& z_{1}, z_{2} \in X, \quad g z_{1} \preceq g z_{2} \quad \Rightarrow \quad F(x, y, z 1, w) \preceq F\left(x, y, z_{2}, w\right) \quad \text { and } \\
& w_{1}, w_{2} \in X, \quad g w_{1} \preceq g w_{2} \quad \Rightarrow \quad F\left(x, y, z, w_{1}\right) \succeq F\left(x, y, z, w_{2}\right) .
\end{aligned}
$$

It is very natural to extend the definition of two-dimensional fixed point (coupled fixed point), three-dimensional fixed point (tripled fixed point) and so on to multidimensional fixed point (n-tuple fixed point) (see, e.g., [9-17]). In this paper, we give some remarks on the notion of $n$-tuple fixed point given by Ertürk and Karakaya in $[18,19]$. Notice that the authors preferred to say ' $n$-tuplet fixed point' instead of ' $n$-tuple fixed point'.

Definition 1.9 (See [18]) An element $\left(x^{1}, x^{2}, x^{3}, \ldots, x^{n}\right) \in X^{n}$ is called an $n$-tuple fixed point of the mapping $F: X^{n} \rightarrow X$ if

$$
\begin{aligned}
& x^{1}=F\left(x^{1}, x^{2}, x^{3}, \ldots, x^{n}\right), \\
& x^{2}=F\left(x^{2}, x^{3}, \ldots, x^{n}, x^{1}\right), \\
& x^{3}=F\left(x^{3}, \ldots, x^{n}, x^{1}, x^{2}\right), \\
& \vdots \\
& x^{n}=F\left(x^{n}, x^{1}, x^{2}, \ldots, x^{n-1}\right) .
\end{aligned}
$$

Definition 1.10 (See [18]) Let $(X, \preceq)$ be a partially ordered set, and let $F: X^{n} \rightarrow X$ be a mapping. We say that $F$ has the mixed monotone property if $F\left(x^{1}, x^{2}, x^{3}, \ldots, x^{n}\right)$ is nondecreasing in odd arguments and it is non-increasing in its even arguments, that is, for any $x^{1}, x^{2}, x^{3}, \ldots, x^{n} \in X$,

$$
\begin{aligned}
& y_{1}, z_{1} \in X, \quad y_{1} \preceq z_{1} \quad \Rightarrow \quad F\left(y_{1}, x^{2}, x^{3}, \ldots, x^{n}\right) \preceq F\left(z_{1}, x^{2}, x^{3}, \ldots, x^{n}\right), \\
& y_{2}, z_{2} \in X, \quad y_{2} \preceq z_{2} \quad \Rightarrow \quad F\left(x^{1}, y_{2}, x^{3}, \ldots, x^{n}\right) \succeq F\left(x^{1}, z_{2}, x^{3}, \ldots, x^{n}\right), \\
& \vdots \\
& y_{n}, z_{n} \in X, \quad y_{n} \preceq z_{n} \quad \Rightarrow \quad F\left(x^{1}, x^{2}, x^{3}, \ldots, y_{n}\right) \preceq F\left(x^{1}, x^{2}, x^{3}, \ldots, z_{n}\right) \quad \text { if } n \text { is odd, } \\
& y_{n}, z_{n} \in X, \quad y_{n} \preceq z_{n} \quad \Rightarrow \quad F\left(\left(x^{1}, x^{2}, x^{3}, \ldots, y_{n}\right) \succeq F\left(x^{1}, x^{2}, x^{3}, \ldots, z_{n}\right) \quad \text { if } n\right. \text { is even. }
\end{aligned}
$$

Definition 1.11 (See [18]) An element $\left(x^{1}, x^{2}, x^{3}, \ldots, x^{n}\right) \in X^{n}$ is called an $n$-tuple coincidence point of the mappings $F: X^{n} \rightarrow X$ and $g: X \rightarrow X$ if

$$
\begin{aligned}
& g x^{1}=F\left(x^{1}, x^{2}, x^{3}, \ldots, x^{n}\right), \\
& g x^{2}=F\left(x^{2}, x^{3}, \ldots, x^{n}, x^{1}\right),
\end{aligned}
$$




$$
\begin{aligned}
& g x^{3}=F\left(x^{3}, \ldots, x^{n}, x^{1}, x^{2}\right), \\
& \vdots \\
& g x^{n}=F\left(x^{n}, x^{1}, x^{2}, \ldots, x^{n-1}\right) .
\end{aligned}
$$

Definition 1.12 (See [18]) Let $(X, \preceq)$ be a partially ordered set, and let $F: X^{n} \rightarrow X$ and $g: X \rightarrow X$ be mappings. We say that $F$ has the mixed $g$-monotone property if $F\left(x^{1}, x^{2}, x^{3}, \ldots, x^{n}\right)$ is $g$-non-decreasing in odd arguments and it is $g$-non-increasing in its even arguments, that is, for any $x^{1}, x^{2}, x^{3}, \ldots, x^{n} \in X$,

$$
\begin{aligned}
& y_{1}, z_{1} \in X, \quad g y_{1} \preceq g z_{1} \quad \Rightarrow \quad F\left(y_{1}, x^{2}, x^{3}, \ldots, x^{n}\right) \preceq F\left(z_{1}, x^{2}, x^{3}, \ldots, x^{n}\right), \\
& y_{2}, z_{2} \in X, \quad g y_{2} \preceq g z_{2} \quad \Rightarrow \quad F\left(x^{1}, y_{2}, x^{3}, \ldots, x^{n}\right) \succeq F\left(x^{1}, z_{2}, x^{3}, \ldots, x^{n}\right), \\
& \vdots \\
& y_{n}, z_{n} \in X, \quad g y_{n} \preceq g z_{n} \quad \Rightarrow \quad F\left(x^{1}, x^{2}, x^{3}, \ldots, y_{n}\right) \preceq F\left(x^{1}, x^{2}, x^{3}, \ldots, z_{n}\right) \quad \text { if } n \text { is odd, } \\
& y_{n}, z_{n} \in X, \quad g y_{n} \preceq g z_{n} \quad \Rightarrow \quad F\left(x^{1}, x^{2}, x^{3}, \ldots, y_{n}\right) \succeq F\left(x^{1}, x^{2}, x^{3}, \ldots, z_{n}\right) \quad \text { if } n \text { is even. }
\end{aligned}
$$

\section{Some remarks}

Firstly we notice that in the case $n=3$, Definitions 1.9 and 1.11 ,

$$
\begin{aligned}
& g x^{1}=F\left(x^{1}, x^{2}, x^{3}\right), \\
& g x^{2}=F\left(x^{2}, x^{3}, x^{1}\right), \\
& g x^{3}=F\left(x^{3}, x^{1}, x^{2}\right),
\end{aligned}
$$

do not extend the notion of tripled coincidence point by Berinde and Borcut [4]. Therefore, their results are not extensions of the well-known results in the tripled case. This fact shows that the odd case is not well posed by Definitions 1.9 and 1.11 or, more precisely, the mixed monotone property is not useful to ensure the existence of coincidence points. In this sense, we have the following result.

Theorem 2.1 Theorem 1 in [18] is not valid if $n$ is odd.

Proof In order not to complicate the proof, we only study the case $n=3$, which is very illustrative and can be identically extrapolated to the case in which $n$ is odd. Let us follow the lines in the proof of Theorem 1 in [18]. Using the initial points $x_{0}^{1}, x_{0}^{2}, x_{0}^{3} \in X$, it is possible to construct three sequences $\left\{x_{k}^{1}\right\},\left\{x_{k}^{2}\right\}$ and $\left\{x_{k}^{3}\right\}$ recursively defined by:

$$
\begin{aligned}
& g x_{k}^{1}=F\left(x_{k-1}^{1}, x_{k-1}^{2}, x_{k-1}^{3}\right), \\
& g x_{k}^{2}=F\left(x_{k-1}^{2}, x_{k-1}^{3}, x_{k-1}^{1}\right), \\
& g x_{k}^{3}=F\left(x_{k-1}^{3}, x_{k-1}^{1}, x_{k-1}^{2}\right) \quad \text { for all } k \in \mathbb{N}, k \geq 1 .
\end{aligned}
$$


By assumption, we have that

$$
\begin{aligned}
& g x_{0}^{1} \preceq F\left(x_{0}^{1}, x_{0}^{2}, x_{0}^{3}\right)=g x_{1}^{1}, \\
& g x_{0}^{2} \succeq F\left(x_{0}^{2}, x_{0}^{3}, x_{0}^{1}\right)=g x_{1}^{2}, \\
& g x_{0}^{3} \preceq F\left(x_{0}^{3}, x_{0}^{1}, x_{0}^{2}\right)=g x_{1}^{3} .
\end{aligned}
$$

Then the authors affirmed that these sequences verify, for all $k \geq 1$,

$$
\begin{aligned}
& g x_{k-1}^{1} \preceq g x_{k}^{1}, \\
& g x_{k-1}^{2} \succeq g x_{k}^{2}, \\
& g x_{k-1}^{3} \preceq g x_{k}^{3} .
\end{aligned}
$$

However, it is impossible to prove that $g x_{1}^{2} \succeq g x_{2}^{2}$ because the mixed $g$-monotone property leads to contrary inequalities. At most, we can deduce the following properties:

$$
g x_{1}^{2} \preceq g x_{0}^{2} \Rightarrow F\left(x_{1}^{2}, x_{0}^{3}, x_{0}^{1}\right) \preceq F\left(x_{0}^{2}, x_{0}^{3}, x_{0}^{1}\right)=g x_{1}^{2} .
$$

Moreover,

$$
g x_{0}^{3} \preceq g x_{1}^{3} \Rightarrow F\left(x_{1}^{2}, x_{0}^{3}, x_{0}^{1}\right) \succeq F\left(x_{1}^{2}, x_{1}^{3}, x_{0}^{1}\right) .
$$

Joining the two previous inequalities, we obtain

$$
F\left(x_{1}^{2}, x_{1}^{3}, x_{0}^{1}\right) \preceq F\left(x_{1}^{2}, x_{0}^{3}, x_{0}^{1}\right) \preceq F\left(x_{0}^{2}, x_{0}^{3}, x_{0}^{1}\right)=g x_{1}^{2} .
$$

However, in the third component, the inequality is on the contrary

$$
g x_{0}^{1} \preceq g x_{1}^{1} \Rightarrow F\left(x_{1}^{2}, x_{1}^{3}, x_{0}^{1}\right) \preceq F\left(x_{1}^{2}, x_{1}^{3}, x_{1}^{1}\right)=g x_{2}^{2} .
$$

Then we can deduce that

$$
F\left(x_{1}^{2}, x_{1}^{3}, x_{0}^{1}\right) \preceq g x_{1}^{2} \quad \text { and } \quad F\left(x_{1}^{2}, x_{1}^{3}, x_{0}^{1}\right) \preceq g x_{2}^{2} .
$$

Since other possibilities yield similar incomparable cases, we cannot get the inequality $g x_{1}^{2} \succeq g x_{2}^{2}$.

For completeness and to conclude this paper, instead of Definitions 1.9 and 1.11, we recall here the concept of multidimensional fixed/coincidence point introduced by Roldán et al. in [11] (see also [12-14]), which is an extension of Berzig and Samet's notion given in [10].

Fix $n \in \mathbb{N}$ such that $n \geq 2$. To separate the variables, let $\{A, B\}$ be a partition of $\Lambda_{n}=$ $\{1,2, \ldots, n\}$, that is, $A \cup B=\Lambda_{n}$ and $A \cap B=\varnothing$, and suppose that $A$ and $B$ are non-empty. We will define

$$
\begin{aligned}
& \Omega_{A, B}=\left\{\sigma: \Lambda_{n} \rightarrow \Lambda_{n}: \sigma(A) \subseteq A \text { and } \sigma(B) \subseteq B\right\} \quad \text { and } \\
& \Omega_{A, B}^{\prime}=\left\{\sigma: \Lambda_{n} \rightarrow \Lambda_{n}: \sigma(A) \subseteq B \text { and } \sigma(B) \subseteq A\right\}
\end{aligned}
$$


Let $\sigma_{1}, \sigma_{2}, \ldots, \sigma_{n}: \Lambda_{n} \rightarrow \Lambda_{n}$ be $n$ mappings from $\Lambda_{n}$ into itself, and let $\Phi$ be the $n$-tuple $\left(\sigma_{1}, \sigma_{2}, \ldots, \sigma_{n}\right)$.

Let $F: X^{n} \rightarrow X$ and $g: X \rightarrow X$ be two mappings.

Definition 2.2 [11] A point $\left(x_{1}, x_{2}, \ldots, x_{n}\right) \in X^{n}$ is called a $\Phi$-coincidence point of the mappings $F$ and $g$ if

$$
F\left(x_{\sigma_{i}(1)}, x_{\sigma_{i}(2)}, \ldots, x_{\sigma_{i}(n)}\right)=g x_{i} \quad \text { for all } i \in\{1,2, \ldots, n\} .
$$

If $g$ is the identity mapping on $X$, then $\left(x_{1}, x_{2}, \ldots, x_{n}\right) \in X^{n}$ is called a $\Phi$-fixed point of the mapping $F$.

Definition 2.3 [11] Let $(X, \preccurlyeq)$ be a partially ordered space. We say that $F$ has the mixed $g$-monotone property (w.r.t. $\{A, B\}$ ) if $F$ is $g$-monotone non-decreasing in arguments of $A$ and $g$-monotone non-increasing in arguments of $B$, i.e., for all $x_{1}, x_{2}, \ldots, x_{n}, y, z \in X$ and all $i$,

$$
g y \preccurlyeq g z \Rightarrow \begin{cases}F\left(x_{1}, \ldots, x_{i-1}, y, x_{i+1}, \ldots, x_{n}\right) \preccurlyeq F\left(x_{1}, \ldots, x_{i-1}, z, x_{i+1}, \ldots, x_{n}\right) & \text { if } i \in A, \\ F\left(x_{1}, \ldots, x_{i-1}, y, x_{i+1}, \ldots, x_{n}\right) \succcurlyeq F\left(x_{1}, \ldots, x_{i-1}, z, x_{i+1}, \ldots, x_{n}\right) & \text { if } i \in B .\end{cases}
$$

In order to ensure the existence of $\Phi$-coincidence/fixed points, it is very important to assume that the mixed $g$-monotone property is compatible with the permutation of the variables, that is, the mappings of $\Phi=\left(\sigma_{1}, \sigma_{2}, \ldots, \sigma_{n}\right)$ should verify:

$$
\sigma_{i} \in \Omega_{A, B} \quad \text { if } i \in A \quad \text { and } \quad \sigma_{i} \in \Omega_{A, B}^{\prime} \quad \text { if } i \in B
$$

Notice that, in fact, when $n$ is even, Definitions 1.11 and 1.12 can be seen as particular cases of the previous definitions, when $A$ is the set of all odd numbers and $B$ is the family of all even numbers in $\{1,2, \ldots, n\}$, and the mappings $\sigma_{1}, \sigma_{2}, \ldots, \sigma_{n}$ are appropriate permutations of the variables.

Finally, to be fair, we remark that most of multidimensional fixed point theorems can be reduced to one-dimensional (usual) fixed point results (see, e.g., [14, 20]). More precisely, for instance in [14], the authors proved that the first coupled fixed point result, Theorem 2.1 in [2], is a consequence of Theorem 2.1 in [21]. In [20], the authors proved that the initial multidimensional fixed point result, Theorem 9 in [11], can be derived from Theorem 2.1 in [21] either.

\section{Competing interests}

The authors declare that there is no conflict of interests regarding the publication of this article.

Authors' contributions

All authors contributed equally and significantly in writing this article. All authors read and approved the final manuscript.

Author details

'Department of Mathematics, Atilim University, Incek, Ankara 06836, Turkey. ${ }^{2}$ University of Jaén, Campus las Lagunillas s/n, Jaén, 23071, Spain.

\section{Acknowledgements}

The first author was supported by the Research Center, College of Science, King Saud University. The second author was supported by Junta the Andalucía through Projects FQM-268 of the Andalusian CICYE. 


\section{References}

1. Guo, D, Lakshmikantham, V: Coupled fixed points of nonlinear operators with applications. Nonlinear Anal., Theory Methods Appl. 11, 623-632 (1987)

2. Bhaskar, TG, Lakshmikantham, V: Fixed point theory in partially ordered metric spaces and applications. Nonlinear Anal. 65, 1379-1393 (2006)

3. Lakshmikantham, V, Ciric, L: Coupled fixed point theorems for nonlinear contractions in partially ordered metric spaces. Nonlinear Anal. 70, 4341-4349 (2009)

4. Berinde, $\mathrm{V}$, Borcut, M: Tripled fixed point theorems for contractive type mappings in partially ordered metric spaces. Nonlinear Anal. 74(15), 4889-4897 (2011)

5. Karapınar, E: Quartet fixed point for nonlinear contraction. arXiv:1106.5472

6. Karapınar, E: Quadruple fixed point theorems for weak $\phi$-contractions. ISRN Math. Anal. 2011, Article ID 989423 (2011)

7. Karapınar, E, Berinde, V: Quadruple fixed point theorems for nonlinear contractions in partially ordered metric spaces. Banach J. Math. Anal. 6(1), 74-89 (2012)

8. Karapınar, E, Luong, NV: Quadruple fixed point theorems for nonlinear contractions. Comput. Math. Appl. 64 1839-1848 (2012)

9. Paknazar, M, Eshaghi Gordji, M, de la Sen, M, Vaezpour, SM: N-fixed point theorems for nonlinear contractions in partially ordered metric spaces. Fixed Point Theory Appl. 2013, 111 (2013)

10. Berzig, M, Samet, B: An extension of coupled fixed point's concept in higher dimension and applications. Comput. Math. Appl. 63, 1319-1334 (2012)

11. Roldán, A, Martínez-Moreno, J, Roldán, C: Multidimensional fixed point theorems in partially ordered complete metric spaces. J. Math. Anal. Appl. 396(2), 536-545 (2012)

12. Roldán, A, Martínez-Moreno, J, Roldán, C, Karapınar, E: Multidimensional fixed point theorems in partially ordered complete partial metric spaces under $(\psi, \varphi)$-contractivity conditions. Abstr. Appl. Anal. 2013, Article ID 634371 (2013)

13. Karapınar, E, Roldán, A, Martínez-Moreno, J, Roldán, C: Meir-Keeler type multidimensional fixed point theorems in partially ordered metric spaces. Abstr. Appl. Anal. 2013, Article ID 406026 (2013)

14. Roldán, A, Martínez-Moreno, J, Roldán, C, Karapınar, E: Some remarks on multidimensional fixed point theorems. Fixed Point Theory (in press)

15. Aydi, H, Karapinar, E, Zead, M Some tripled coincidence point theorems for almost generalized contractions in ordered metric spaces. Tamkang J. Math. 44(3), 233-251 (2013)

16. Mustafa, Z, Shatanawi, WA, Karapinar, E: Quadruple fixed point theorems under nonlinear contractive conditions in partially ordered metric spaces. J. Appl. Math. 2012, Article ID 951912 (2012)

17. Aydi, H, Karapinar, E, Zead, M Mixed $g$-monotone property and quadruple fixed point theorems in partially ordered metric spaces. Fixed Point Theory Appl. 2012, 71 (2012)

18. Ertürk, M, Karakaya, V: $n$-tuplet fixed point theorems for contractive type mappings in partially ordered metric spaces J. Inequal. Appl. 2013, 196 (2013)

19. Ertürk, M, Karakaya, V: Correction: $n$-tuplet fixed point theorems for contractive type mappings in partially ordered metric spaces. J. Inequal. Appl. 2013, 368 (2013)

20. Samet, B, Karapınar, E, Aydi, H, Rajic, VC: Discussion on some coupled fixed point theorems. Fixed Point Theory Appl. 2013, 50 (2013)

21. Ran, ACM, Reurings, MCB: A fixed point theorem in partially ordered sets and some applications to matrix equations. Proc. Am. Math. Soc. 132, 1435-1443 (2003)

10.1186/1029-242X-2013-567

Cite this article as: Karapınar and Roldán: A note on ' $n$-tuplet fixed point theorems for contractive type mappings in partially ordered metric spaces'. Journal of Inequalities and Applications 2013, 2013:567

\section{Submit your manuscript to a SpringerOpen ${ }^{\circledR}$ journal and benefit from:}

- Convenient online submission

- Rigorous peer review

- Immediate publication on acceptance

- Open access: articles freely available online

- High visibility within the field

- Retaining the copyright to your article 